\title{
Potentiation of taste by another taste during compound aversion learning
}

\author{
MARK E. BOUTON, CHRISTINE M. DUNLAP, and DALE SWARTZENTRUBER \\ University of Vermont, Burlington, Vermont
}

\begin{abstract}
Two experiments with rat subjects examined whether a saccharin taste could potentiate the conditioning of an aversion to a salty taste when the two stimuli were presented together prior to lithium-induced illness. In Experiment 1, a $0.1 \%(\mathrm{w} / \mathrm{v})$ saccharin solution potentiated conditioning of a very dilute $(0.03 \%) \mathrm{NaCl}$ solution, but had no demonstrable effect on two stronger $\mathrm{NaCl}$ solutions ( $0.6 \%$ and $1.2 \%$ ). In Experiment 2, the 0.1\% saccharin solution again potentiated the $0.03 \% \mathrm{NaCl}$ target, but weaker and stronger saccharin concentrations $(0.033 \%$ and $0.3 \%)$ did not. The ability of a taste to potentiate a second taste is not consistent with theories that assume that potentiation is unique to compounds composed of tastes and other, functionally different, nontaste cues. Potentiation may occur when the target stimulus is weakly conditionable on its own and when the particular combination of target and potentiator facilitates perceptual integration of the compound.
\end{abstract}

When rats receive a taste and odor together prior to illness, the taste may facilitate, or "potentiate," the conditioning of an aversion to the odor (e.g., Coburn, Garcia, Kiefer, \& Rusiniak, 1984; Durlach \& Rescorla, 1980; Lett, 1984; Palmerino, Rusiniak, \& Garcia, 1980; Rusiniak, Hankins, Garcia, \& Brett, 1979; Westbrook, Homewood, Horn, \& Clarke, 1983). The fact that taste may potentiate, rather than interfere with or overshadow, conditioning of the odor contradict several models of conditioning that assume that compounded stimuli compete with one another in some fashion to gain associative strength (e.g., Mackintosh, 1975; Pearce \& Hall, 1980; Rescorla \& Wagner, 1972).

Two approaches have been taken to explain potentiation. One approach has expanded on the known principles of conditioning. For example, Durlach and Rescorla (1980; see also Rescorla \& Durlach, 1981) noted that the simultaneous presentation of odor and taste may encourage the learning of an association between them. When odor is tested alone after being conditioned in compound with taste, its strong rejection could therefore result from its associations with both illness and the newly aversive taste. Consistent with this view, some investigators have shown that if the taste aversion is extinguished prior to the odor test, the strength of the odor aversion can also be reduced (Durlach \& Rescorla, 1980; Westbrook et al., 1983; see also Kucharski \& Spear, 1985; but see Lett, 1984). However, because animals form associations between compounded stimuli fairly commonly when the stimuli are presented simultaneously (e.g., Rescorla \& Durlach, 1981), and because simultaneous compounds have histor-

This research was supported by Grants BNS 83-00803 and BNS 8607208 from the National Science Foundation. We thank Kim Deisher for her help with Experiment 2. Send correspondence to Mark E. Bouton, Department of Psychology, University of Vermont, Burlington, VT 05405 . ically yielded both potentiation and overshadowing, this mechanism does not isolate the conditions that lead uniquely to potentiation.

An alternative, functional, approach has been taken by Garcia, Rusiniak, and their collaborators (e.g., Coburn et al., 1984; Garcia, in press; Garcia, Lasiter, BermudezRattoni, \& Deems, 1985; Garcia \& Rusiniak, 1980; Palmerino et al., 1980; Rusiniak et al., 1979). These investigators have shunned the general laws of learning and have instead emphasized the unique functions of odor and taste in the rat's feeding behavior. For example, although taste is a proximal cue that controls the consumption of foods, odor is a nonredundant distal cue that controls approach to those foods (e.g., Garcia, in press; Rusiniak et al., 1979). Proximal taste cues are also used by the "gut defense" system in the avoidance of gastric distress, whereas distal odors are used primarily in other behavioral systems that include, for example, mating and "skin defense"' (e.g., Garcia et al., 1985; cf. Garcia \& Rusiniak, 1980). Tastes may "gate" associations between illness and distal cues that are not preferentially associated with illness. The functional approach generally assumes that potentiation in aversion learning is unique to compounds composed of proximal tastes and other, functionally different, nontaste cues (e.g., Garcia, in press).

In the rat, taste does appear to potentiate several types of nontaste cues besides odor, including visual (Galef \& Osborne, 1978), auditory (Ellins, Cramer, \& Whitmore, 1985) and environmental cues (e.g., Best, Brown, \& Sowell, 1984). But the important assumption that potentiation is unique to taste-nontaste compounds has received very little direct investigation. Bouton and Whiting (1982) set out to examine it by comparing taste-odor and tastetaste compounds in several experiments. Their results suggested little difference between the two types of compounds. Surprisingly, taste typically overshadowed, rather 
than potentiated, the aversions conditioned to both odor and taste targets. Bouton and Whiting's failure to observe odor potentiation is consistent with results from several other laboratories (Ida, 1984; Lashley \& Rosellini, 1986; Mikulka, Pitts, \& Philput, 1982; Rosellini \& Lashley, 1986).

In more recent experiments, Bouton, Jones, McPhillips, and Swartzentruber (1986) isolated some of the conditions that yield odor potentiation. Taste potentiated odor if the odorant (an almond extract) was presented on a "cup" near the drinking spout (Palmerino et al., 1980) instead of being mixed in the drinking water, as it had been before (e.g., Rusiniak et al., 1979). In the latter condition, taste still overshadowed odor. Behavioral observations suggested that the cup odor functioned better as a distal cue; when conditioned, it suppressed the rat's approach to the drinking spout (cf. Rusiniak et al., 1979). But the cup odor's status as a distal cue was not as important as its relatively weak conditionability or low salience as a cue for poison. When the concentration of the odorant in the drink was diluted so that it was similarly weak in conditionability, taste potentiated conditioning of this proximal odor. This result suggests that weak conditionability of the target, rather than its status as a distal cue, may be the key prerequisite for potentiation.

The present experiments pursued this hypothesis further. If potentiation depends primarily on weak target conditionability, then it should be possible to potentiate a proximal, but weakly conditionable, taste stimulus with another taste during aversion conditioning. Such an outcome would not be anticipated by the functional approach to potentiation described above. The present experiments were therefore designed to determine whether a weakly conditionable taste could be potentiated by another taste. Experiment 1 manipulated the concentration of the target taste; Experiment 2 manipulated the concentration of the potentiating taste.

\section{EXPERIMENT 1}

In the first experiment, three different concentrations of a salty taste were conditioned either alone or in compound with a $0.1 \%$ saccharin solution. The concentration of salt was expected to affect its ease of conditioning. The question was whether it would also affect the degree to which it would be potentiated by saccharin (cf. Bouton et al., 1986, Experiment 4).

\section{Method}

\section{Subjects}

The subjects were 36 female Wistar rats, bred at the University of Vermont and 130 days old at the start of the experiment. The rats had previously participated in an experiment in which they had been food-deprived, trained to leverpress for food, and exposed to tones, lights, and mild footshocks. Food was available ad lib for a week prior to the present experiment, and group assignment was random with respect to prior treatment. The rats were housed individually in stainless steel cages in a room maintained on a 14:10-h light:dark cycle. The experiment was run on consecutive days during the light portion of the cycle.

\section{Apparatus}

The experiment was conducted in a set of four "conditioning boxes" housed in a room several meters down the hall from the home colony room. Each box measured $16.5 \times 31 \times 22 \mathrm{~cm}$. The ceiling and three walls of the chamber were made of wood (painted white): one of the long walls was clear acrylic plastic. The floor was composed of 3-mm brass rods spaced $1 \mathrm{~cm}$ apart. Solutions were delivered through a standard stainless steel spout (Girton) that extended $1.5 \mathrm{~cm}$ out of a stainless steel cup that was embedded in a side wall. The cup, which was $4.5 \mathrm{~cm}$ in diameter and $3 \mathrm{~cm}$ deep, was covered with hardware cloth.

All solutions were mixed in distilled water. The three target salty tastes were provided by $0.03 \%, 0.6 \%$, and $1.2 \%(w / v)$ solutions of $\mathrm{NaCl}$. When compounded with saccharin, the $\mathrm{NaCl}$ was mixed with a $0.1 \%$ saccharin solution in a manner that preserved the individual concentrations.

\section{Procedure}

Drink training. The rats were initially trained to drink distilled water in the conditioning boxes over a series of seven daily 10 -min drink sessions. The animals were water-deprived except for the drink in the conditioning box and a second 10-min drink in the home cage that occurred approximately $\mathbf{3 0} \mathrm{min}$ following the first drink. Food was available on an ad-lib basis in the home cage, but was removed prior to the first drink and returned following the second. The animals were weighed each day prior to their transport to the conditioning boxes.

Conditioning. Following drink training, the rats were assigned to six groups $(n=6)$ matched on mean intake in the conditioning boxes during the final 3 days of drink training. Conditioning was then conducted over the next 6 days. On Days 1 and 4, the rats received experimental solutions while they drank for the usual $10 \mathrm{~min}$ in the conditioning boxes. They were then returned to the home cage, and $30 \mathrm{~min}$ later were injected intraperitoneally with a $5-\mathrm{ml} / \mathrm{kg}$ dose of a $0.6-\mathrm{M}$ lithium chloride solution. Distilled water was made available in the home cage for $10 \mathrm{~min}$ approximately $90 \mathrm{~min}$ after injection. The groups differed only in terms of the solution they received in the conditioning boxes. Two groups received the $0.03 \% \mathrm{NaCl}$ solution, two received the $0.6 \%$ solution, and two received the $1.2 \%$ solution. One group from each condition received the $\mathrm{NaCl}$ mixed with $0.1 \%$ saccharin; the other received $\mathrm{NaCl}$ alone. Days 2, 3, 5, and 6 were water-recovery days in which the rats received 10 -min drinks in the conditioning boxes and home cage following the procedure used during drink training.

Testing. Aversions to the $\mathrm{NaCl}$ solutions alone were then tested over a series of five daily tests conducted in the conditioning boxes. Every rat received $\mathrm{NaCl}$ alone in the concentration that had been presented during conditioning. The procedure followed that used during conditioning except that no lithium was administered; as usual, a 10-min drink of distilled water in the home cage followed each 10 -min test in the conditioning box by approximately $30 \mathrm{~min}$.

The rejection criterion was set at $p<.05$ for all statistical tests.

\section{Results}

Mean fluid consumption of the groups during the conditioning and test trials is presented in Figure 1. As the figure suggests, aversion conditioning generally improved as the $\mathrm{NaCl}$ concentration was increased. And more important, saccharin during conditioning potentiated the conditioning of the weakest $(0.03 \%) \mathrm{NaCl}$ solution.

\section{Conditioning}

Consumption on the two conditioning trials was analyzed with a target concentration $\times$ compound $\times$ trial analysis of variance (ANOVA), which revealed signifi- 


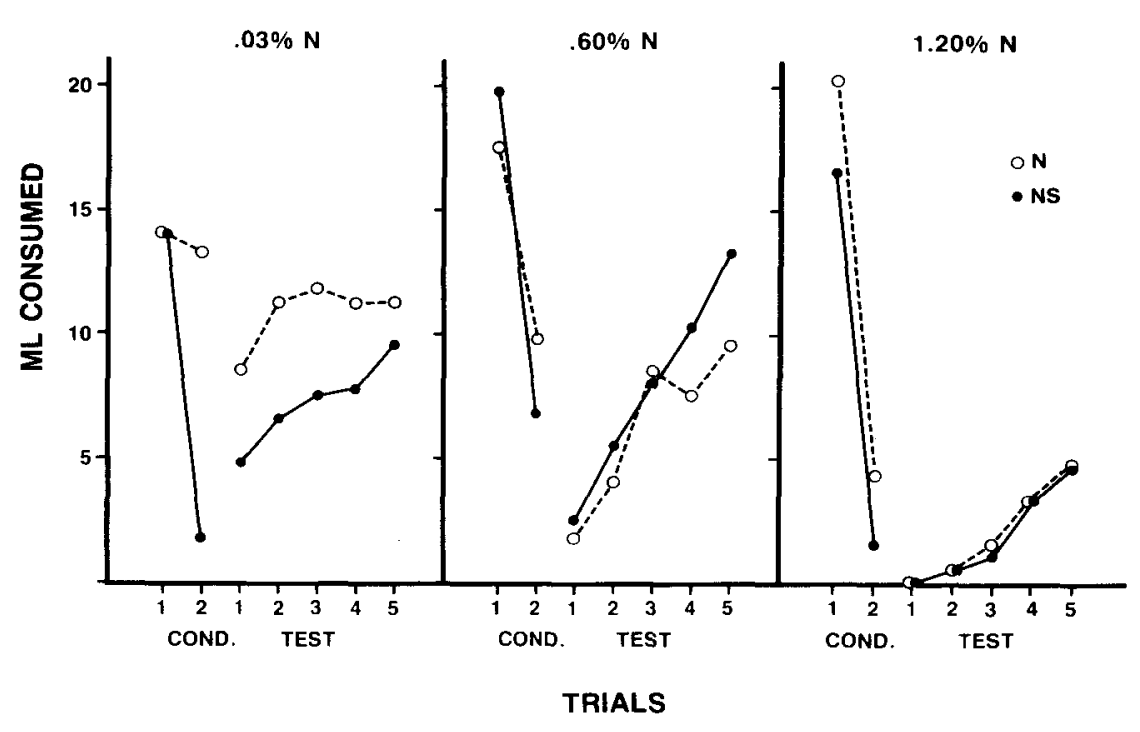

Figure 1. Mean consumption of the experimental solutions during conditioning and testing in Experiment 1. $\mathrm{N}=\mathrm{NaCl} ; \mathrm{S}=$ saccharin $(0.1 \%)$.

cant main effects of the target concentration $[F(2,30)=$ $3.56]$, compound $[F(1,30)=10.41]$, and trial factors $[F(1,30)=238.74]$. The target concentration and compound factors both interacted significantly with trial $\left(F_{\mathrm{S}}\right.$ $>14.07)$. The target $\times$ compound $\times$ trial interaction was also highly reliable $[F(2,30)=7.16]$, although the simple target $\times$ compound interaction was not $[F(2,30)$ $=2.49$ ]. Simple effect tests using the methods described by Howell (1982) indicated that the group that received conditioning with the weakest $(0.03 \%) \mathrm{NaCl}$ solution by itself was the only group that did not decrease consumption on the second conditioning trial $[F(1,30)<1$; all other $\left.F_{\mathrm{S}}(1,30)>21.50\right]$.

Consumption on the first conditioning trial was analyzed separately to assess the rats' initial reactions to the experimental solutions. A target concentration $\times$ compound ANOVA revealed no main effect of compound $[F(1,30)$ $<1$ ]; the presence of saccharin failed to suppress consumption of $\mathrm{NaCl}$ (cf. Rusiniak et al., 1979). The main effect of the $\mathrm{NaCl}$ concentration, however, was reliable $[F(2,30)=5.54]$. The solutions containing $0.03 \% \mathrm{NaCl}$ were consumed significantly less than the solutions containing the other two $\mathrm{NaCl}$ concentrations $\left[F_{\mathrm{s}}(1,30)\right.$ $>7.67]$, which did not differ reliably $[F(1,30)<1]$. The target concentration $\times$ compound interaction was not significant $[F(2,30)=1.84]$.

\section{Testing}

Consumption of the $\mathrm{NaCl}$ targets alone over all five test trials was analyzed with a target concentration $\times$ compound $x$ trial ANOVA. The analysis revealed a reliable main effect of target concentration $[F(2,30)=18.65]$ and a reliable target concentration $\times$ trial interaction $[F(8,120)$ $=3.16$ ]. Although consumption generally increased due to extinction over the five test trials $[F(4,120)=26.42]$, weaker conditioning clearly occurred with the weaker $\mathrm{NaCl}$ concentrations. The compound main effect $[F(1,30)$ $<1]$, the compound $\times$ concentration interaction $[F(2,30)$ $=2.48$ ], and all combinations of the compound and trial factors $(F \mathrm{~s}<1)$ were not statistically reliable. However, a priori comparisons of the two groups that received conditioning at each level of $\mathrm{NaCl}$ concentration (collapsed over trials) revealed significant potentiation by saccharin at the $0.03 \% \mathrm{NaCl}$ concentration $[F(1,30)=4.46]$ and no effect of saccharin at either the $0.6 \%$ or $1.2 \%$ concentration $\left[F_{\mathrm{S}}(1,30)<1\right]$.

\section{Discussion}

The conditionability of the $\mathrm{NaCl}$ taste, or the extent to which its intake was suppressed following its conditioning with $\mathrm{LiCl}$ alone, decreased as the $\mathrm{NaCl}$ concentration was diluted. At the same time, the probability that the $\mathrm{NaCl}$ taste would be potentiated by saccharin also increased. These results parallel those reported by Bouton et al. (1986, Experiment 4) for an almond odorant target mixed in drinking water. Consistent with the conditionability hypothesis, odor and taste targets may both be potentiated by saccharin if they are relatively weak in conditionability when paired with toxin alone.

The strongest of the present target $\mathrm{NaCl}$ concentrations $(1.2 \%)$ was the same as a $0.2-\mathrm{M} \mathrm{NaCl}$ solution used previously by Bouton and Whiting (1982, Experiments 1-3). In contrast to the results of the earlier experiments, there was no evidence that saccharin overshadowed or attenuated $\mathrm{NaCl}$ conditioning here. The present procedure differed, however, from that of the previous experiments in many respects, including the duration of exposure to the flavor during the conditioning trials $(10 \mathrm{vs} .20 \mathrm{~min})$, the location of that exposure (the conditioning boxes vs. 
the home cage), the type of taste that was compounded with the $\mathrm{NaCl}(0.1 \%$ saccharin vs. $0.2 \%$ saccharin or $0.1-\mathrm{M}$ sucrose), and the flavor- $\mathrm{LiCl}$ interval ( $30 \mathrm{~min}$ vs. $<10 \mathrm{~min}$; but see Bouton \& Whiting, 1982, Experiment 3 ).

\section{EXPERIMENT 2}

One purpose of the second experiment was to replicate the potentiation of $0.03 \% \mathrm{NaCl}$ that was observed in the preceding experiment. A second purpose was to examine the effect of the concentration of saccharin on the conditioning of $\mathrm{NaCl}$. Compound conditioning models predict increased overshadowing of the target as the compounded stimulus's intensity is increased (Mackintosh, 1975; Pearce \& Hall, 1980; Rescorla \& Wagner, 1972). In experiments in which auditory and visual stimuli are used as predictors of footshock, strong cues do appear to overshadow weaker cues in an intensity-dependent manner (Mackintosh, 1976). In contrast, Rusiniak et al. (1979) reported increasing potentiation of a $2.0 \%$ almond drink odor as the concentration of the saccharin compounded with it was increased. In the present experiment, $0.03 \%$ $\mathrm{NaCl}$ was conditioned either alone or in compound with $0.033 \%, 0.1 \%$, or $0.3 \%$ saccharin.

\section{Method}

\section{Subjects and Apparatus}

The subjects were 63 Wistar rats whose ages and prior experimental histories were similar to those in the preceding experiment. The study was run in two replications; 28 females were involved in the first, and 26 females and 9 males (randomly distributed among the groups) were involved in the second. The procedures used in the two replications were identical except as noted. In both replications, the apparatus, housing, and maintenance conditions were the same as in Experiment 1.

\section{Procedure}

Following 9 days of drink training with the procedure used in Experiment 1, the rats were assigned to four groups matched in water intake in the conditioning boxes over the last 3 days of drink training. Two conditioning trials were then administered following the procedure used before. During the conditioning trials, one group ( $n \mathrm{~s}=7$ and 9 in Replications 1 and 2 , respectively) received conditioning with the $0.03 \% \mathrm{NaCl}$ solution alone; the three remaining groups received the $\mathrm{NaCl}$ in compound with $0.033 \%$ saccharin ( $n \mathrm{~s}=7$ and 9 ), $0.1 \%$ saccharin ( $n \mathrm{~s}=7$ and 9 ), or $0.3 \%$ saccharin ( $n s=7$ and 8). As usual, the compounds were mixed in distilled water in a fashion that preserved the concentrations of the individual elements.

Following the 2 water-recovery days that followed the second conditioning trial, all groups received three 10 -min tests (on consecutive days) with the $0.03 \% \mathrm{NaCl}$ solution alone. Testing proceeded as in Experiment 1.

\section{Results}

Figure 2 presents the mean intake of each group during conditioning and during the tests of the $0.03 \% \mathrm{NaCl}$ solution alone. The consumption of the control group that received $\mathrm{NaCl}$ by itself during conditioning is shown in each of the panels to facilitate comparisons. Potentiation of the $\mathrm{NaCl}$ taste was again obtained, but only when $\mathrm{NaCl}$ was compounded with the intermediate $(0.1 \%)$ saccharin concentration during conditioning.

\section{Conditioning}

Consumption during the conditioning trials was analyzed with a group $\times$ trials ANOVA. (For simplicity, all ANOVAs reported here collapsed over the replication factor, which never interacted significantly with another factor; all $p \mathrm{~s}>.05$.) The analysis revealed a reliable group effect $[F(3,59)=29.73]$, trial effect $[F(1,59)=219.30]$, and a group $\times$ trial interaction $[F(3,59)=31.59]$. The interaction was due to the fact that the control group's

$.03 \% \mathrm{~S}$

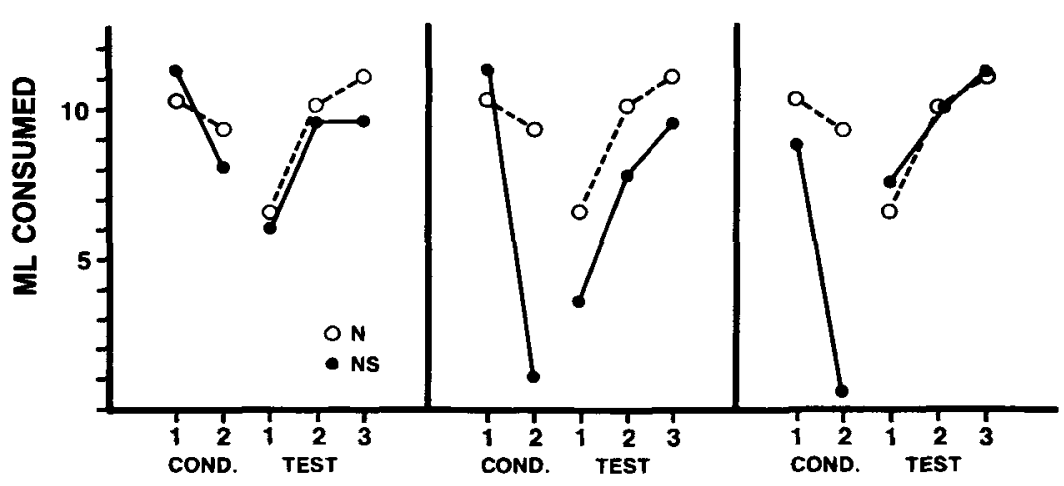

TRIALS

Figure 2. Mean consumption of the experimental solutions during conditioning and testing in Experiment 2. The group that received conditioning with $\mathrm{NaCl}$ alone (open circles) is shown in each of the panels. $\mathrm{S}=$ saccharin; $\mathrm{N}=\mathrm{NaCl}(0.03 \%)$. 
consumption did not change over trials $[F(1,59)=1.68]$, whereas that of each of the other groups decreased $[F \mathrm{~s}(1,59)>19.0]$. A separate one-way ANOVA on the first trial alone indicated a reliable difference among the groups $[F(3,59)=2.93]$ that was due primarily to the fact that the $0.3 \%$ saccharin compound was consumed reliably less than either of the other two compounds $[F \mathrm{~s}(1,59)>6.62]$. Consumption of $\mathrm{NaCl}$ alone by the control was not different from consumption of any of the compounds $\left[F_{\mathrm{S}}(1,59)<2.44\right]$.

\section{Testing}

Because no floor effects were evident at the outset of testing, statistical analyses focused on the first test trial. A one-way ANOVA revealed a reliable overall difference among the groups $[F(3,59)=3.59]$. Planned comparisons of each of the compound groups with the control indicated reliable potentiation in the group that had received the compound containing the intermediate $(0.1 \%)$ saccharin concentration $[F(1,59)=5.96]$. In contrast, consumption in the remaining two compound groups did not differ significantly from that of the control $\left[F_{\mathrm{s}}(1,59)<1\right]$. These data replicate the potentiation observed in the preceding experiment, and suggest that the present $\mathrm{NaCl}$ solution is potentiated only by saccharin of a relatively moderate concentration.

\section{Discussion}

As in Experiment 1, conditioning of the present $0.03 \%$ $\mathrm{NaCl}$ target taste was potentiated when it was compounded with $0.1 \%$ saccharin during conditioning. However, that result was not obtained with weaker or stronger concentrations of saccharin. The present nonmonotonic relationship between saccharin concentration and the strength of potentiation appears to contrast with the results reported by Rusiniak et al. (1979) with a $2.0 \%$ almond-drink odor target. It should be noted, however, that Rusiniak et al. investigated a different set of saccharin concentrations (" $0.0 \%, " 0.0125 \%, 0.05 \%$, and $0.2 \%$ ); their results indicated significant (and comparable) potentiation with $0.05 \%$ and $0.2 \%$ saccharin, but no potentiation with $0.0125 \%$. It is possible that the present results would have been quite similar had we used $0.2 \%$ instead of $0.3 \%$ as our maximum saccharin concentration. The present data strongly suggest that with the present procedures and materials, optimal combinations of target (Experiment 1) and potentiating taste concentrations (Experiment 2) do exist for the production of potentiation.

\section{GENERAL DISCUSSION}

The results reported here suggest that the presence of a second taste may sometimes potentiate conditioning to a target taste when the two are compounded during aversion learning. Contrary to views that attribute potentiation to unique interactions between taste and nontaste cues in poison avoidance learning (e.g., Coburn et al., 1984;
Garcia, in press; Garcia et al., 1985; Garcia \& Rusiniak, 1980; Palmerino et al., 1980; Rusiniak et al., 1979), potentiation does not appear to be a unique property of taste-nontaste combinations. In fact, much of the evidence suggests that tastes and odors, at least, have reasonably similar properties when they are used as targets in compound conditioning experiments. Depending on their conditionability, we have now observed both potentiation and overshadowing with both taste and odor targets (present results; Bouton et al., 1986; Bouton \& Whiting, 1982). This general pattern suggests that if tastes and odors have different functions in the rat's feeding system, the learning mechanism may often ignore them. ${ }^{1}$

As in previous research with odor targets (Bouton et al., 1986), the results of Experiment 1 suggest that a weakly conditionable taste is more susceptible to potentiation than are more strongly conditionable targets. The apparent dependence of potentiation on weak target conditionability may, at least partly, account for previous failures to produce potentiation: Experiments that failed to yield potentiation often involved relatively strongly conditionable targets (see discussion in Bouton et al., 1986). However, the results of Experiment 2 suggest that the concentration of the potentiating taste is also an important factor: Given the use of a potentiatable target, there may be an optimal concentration for the potentiating taste. Taken together, the results of Experiments 1 and 2 suggest that potentiation may depend on the relationship between the concentration of the target and that of the potentiating taste.

This conclusion does not necessarily challenge the view that potentiation is caused by associations learned between the target and potentiator (Durlach \& Rescorla, 1980; Rescorla \& Durlach, 1981). However, that view does not anticipate the present results in any detail. Instead, the importance of the target-potentiator intensity relationship seems more broadly consistent with the view that perceptual combination processes are involved in potentiation (see Rescorla, 1981; Rescorla \& Durlach, 1981; Spear \& Kurcharski, 1984). It may be implausible to think that the animal analyzes a compound flavor into its component parts before the components can become associated. Indeed, it is probable that certain combinations of cues would facilitate an immediate perceptual integration of the compound. When a very weak, but detectable, taste is combined with a moderately intense taste, the rat might be especially likely to perceive the weak target as a feature of the other flavor. Stronger targets may be more readily recognized as separate, competitive, elements. If the compound stimulus is integrated as a unit, potentiation may occur when the unit can be more strongly conditioned than the target alone (cf. Rescorla, 1981; Spear \& Kucharski, 1984). The present data are consistent with the possibility that potentiation occurs under conditions that facilitate perception of the compound as a unit.

It is worth noting that the fact that taste-taste potentiation occurred here under a relatively restricted set of conditions does not necessarily imply that it is less robust than 
taste-odor potentiation. Taste-odor potentiation itself may occur only under a fairly restricted set of conditions (e.g., see Bouton et al., 1986; Bouton \& Whiting, 1982; Ida, 1984; Lashley \& Rosellini, 1986; Mikulka et al., 1982; Rosellini \& Lashley, 1986). Both phenomena are important because they suggest deficiencies in contemporary analyses of compound conditioning. The present data do not necessarily imply that taste-taste and taste-odor potentiation are mediated by the same mechanisms, or that those mechanisms will be adequately described by general principles of conditioning. At present, however, there is little direct evidence that forces rejection of either possibility.

\section{REFERENCES}

Best, M. R., Brown, E. R., \& Sowell, M. K. (1984). Taste-mediated potentiation of noningestional stimuli in rats. Learning \& Motivation, 15, 244-258.

Bouton, M. E., Jones, D. L., McPhillips, S. A., \& SwartzenTRUBER, D. (1986). Potentiation and overshadowing in odor-aversion learning: Role of method of odor presentation, the distal-proximal cue distinction, and the conditionability of odor. Learning \& Motivation, 17, 115-138.

Bouton, M. E., \& Whiting, M. R. (1982). Simultaneous odor-taste and taste-taste compounds in poison-avoidance learning. Learning \& Motivation, 13, 472-494.

Coburn, K. L., Garcia, J., Kiefer, S. W., \& Rusiniak, K. W. (1984). Taste potentiation of poisoned odor by temporal contiguity. Behavioral Neuroscience, 98, 813-819.

Durlach, P. J., \& Rescorla, R. A. (1980). Potentiation rather than overshadowing in flavor-aversion learning: An analysis in terms of within-compound associations. Journal of Experimental Psychology: Animal Behavior Processes, 6, 175-187.

Ellins, S. R., Cramer, R. E., \& Whitmore, C. (1985). Taste potentiation of auditory aversions in rats (Rattus norvegicus): A case for spatial contiguity. Journal of Comparative Psychology, 99, 108-111.

GaleF, B. G., \& OsBorne, B. (1978). Novel taste facilitation of the association of visual cues with toxicosis in rats. Journal of Comparative \& Physiological Psychology, 92, 907-916.

Garcia, J. (in press). Food for Tolman: Cognition and cathexis in concert. In T. Archer \& L.-G. Larsson (Eds.), Avoidance, anxiety, and aversion: Perspectives in aversively motivated behavior. Hillsdale, NJ: Erlbaum.

Garcia, J., Lasiter, P. S., Bermudez-Rattoni, F., \& Deems, D. A. (1985). A general theory of aversion learning. Annals of the New York Academy of Sciences, 443, 8-21.

GarCIA, J., \&usiniaK, K. W. (1980). What the nose learns from the mouth. In D. Muller-Schwarze \& R. M. Silverstein (Eds.), Chemical signals (pp. 141-156). New York: Plenum Press.

Howell, D. C. (1982). Statistical methods for psychology. Boston: Duxbury Press.

IDA, M. (1984). An analysis of potentiation in flavor-aversion learning. Journal of Child Development, 20, 6-12.

KUChARSKI, D., \& SPEAR, N. E. (1985). Potentiation and overshadowing in preweanling and adult rats. Joumal of Experimental Psychology: Animal Behavior Processes, 11, 15-34.

LASHLEY, R. L., \& Rosellini, R. A. (1986). Conditioning of odors in compound with taste is a function of factors other than potentiation. Bulletin of the Psychonomic Society, 24, 159-162.
LETT, B. T. (1984). Extinction of taste aversion does not eliminate taste potentiation of odor aversion in rats or color aversion in pigeons. Animal Learning \& Behavior, 12, 414-420.

Mackintosh, N. J. (1975). A theory of attention: Variations in the associability of stimuli with reinforcement. Psychological Review, 82, 276-298.

MaCKINTOSH, N. I. (1976). Overshadowing and stimulus intensity. Animal Learning \& Behavior, 4, 186-192.

Mikulka, P. J., Pitts, E., \& Philput, C. (1982). Overshadowing not potentiation in taste aversion learning. Bulletin of the Psychonomic Society, 20, 101-104.

Palmerino, C. C., Rusiniak, K. W., \& Garcia, J. (1980). Flavorillness aversions: The peculiar roles of odor and taste in memory for poison. Science, 208, 753-755.

Pearce, J. M., \& Hall, G. (1980). A model for Pavlovian leaming: Variations in the effectiveness of conditioned but not of unconditioned stimuli. Psychological Review, 87, 532-552.

Peterson, C. S., Valliere, W. A., Misanin, J. R., \& Hinderluter, C. F. (1985). Age differences in the potentiation of taste aversion by odor cues. Physiological Psychology, 13, 103-106.

Rescorla, R. A. (1981). Simultaneous associations. In P. Harzem \& M. D. Zeiler (Eds.), Predictability, correlation, and contiguity (pp. 4780). New York: Wiley.

Rescorla, R. A., \& Durlach, P. J. (1981). Within-event learning in Pavlovian conditioning. In N. E. Spear \& R. R. Miller (Eds.), Information processing in animals: Memory mechanisms (pp. 81-112). Hillsdale, NJ: Erlbaum.

Rescorla, R. A., \& WAgner, A. R. (1972). A theory of Pavlovian conditioning: Variations in the effectiveness of reinforcement and nonreinforcement. In A. H. Black \& W. F. Prokasy (Eds.), Classical conditioning: II. Current research and theory (pp. 64-99). New York: Appleton-Century-Crofts.

Rosellini, R. A., \& LASHley, R. L. (1986). Conditioning of odors in compound with taste: A failure to observe potentiation. Bulletin of the Psychonomic Society, 24, 55-58.

Rusiniak, K. W., Hankins, W. G., Garcia, J., \& Brett, L. P. (1979). Flavor-illness aversions: Potentiation of odor by taste in rats. Behavioral \& Neural Biology, 25, 1-17.

SPEAR, N. E., \& Kucharski, D. (1984). Ontogenetic differences in the processing of multi-element stimuli. In H. L. Roitblat, T. G. Bever, \& H. A. Terrace (Eds.), Animal cognition (pp. 545-567). Hillsdale, NJ: Erlbaum.

Westbrook, R. F., Homewood, J., Horn, K., \& Clarke, J. C. (1983). Flavour-odour compound conditioning: Odour-potentiation and flavour-attenuation. Quarterly Journal of Experimental Psychology, 35B, 13-33.

\section{NOTE}

1. Tastes have actually been potentiated by odors in preweanling rats (Spear \& Kucharski, 1984) and adult rats under some circumstances (Peterson, Valliere, Misanin, \& Hinderliter, 1985; but see Westbrook et al., 1983). In addition, Kucharski and Spear (1985) found that a coffee flavor (probably composed of both odor and taste) might potentiate a sucrose taste (and vice versa) in adults and, especially, preweanlings. Like the present results, such findings suggest that the potentiation mechanism may be "blind" to the qualitative nature of the compounded cues. We should note, however, that we were unable to potentiate aversion conditioning to a target odor with a second odor in one attempt to do so with adult subjects (Bouton et al., 1986, Experiment 3).

(Manuscript received January 29, 1987; revision accepted for publication June $11,1987$. 